\title{
Assessment of the value of technician reporting of electrocardiographs in an accident and emergency department
}

\author{
M Dudley, K S Channer
}

\begin{abstract}
Objective-To assess the value of a cardiac technicians' report on electrocardiographs (ECGs) in reducing serious errors of interpretation by senior house officers. Methods-A parallel study of interpretation of ECGs by senior house officers from 238 cases seen in an accident and emergency (A\&E) department in a teaching hospital. 129 ECGs were reported by a cardiac technician at the time of recording and before the senior house officer wrote a report, and 109 were reported only by the senior house officers. Misinterpretations by doctors and technicians were graded by a consultant cardiologist on a four point scale and compared in the two groups. Serious errors (grade 4) were defined as those which potentially affected immediate management.
\end{abstract}

Results-The number of grade 4 errors of interpretation of ECGs by $A \& E$ senior house officers was reduced by $59 \%$ when there was a prior technical report (mean (SD), 18(17)\% $v 6$ (7)\%; Fisher's exact test $P<0.05)$.

Conclusions-When cardiac technicians provide a report on an ECG at the time of its recording, serious errors of interpretation by senior house officers are reduced.

$(\Im$ Accid Emerg Med 1997;14:307-310)

Keywords: electrocardiograph; accident and emergency department; cardiographers

Staff in the accident and emergency (A\&E) department at the Royal Hallamshire Hospital in Sheffield saw approximately 54000 adult patients in 1994/95. Of these, 9023 (17\%) were classified as being "medical", and 3897 $(43 \%)$ of these were admitted. About one third of medical admissions through the $A \& E$ department are due to cardiovascular disease. The symptoms of chest pain associated with ischaemic heart disease and breathlessness associated with heart failure are predominant. In these patients, the most commonly performed diagnostic investigation, after full clinical evaluation, is the electrocardiograph (ECG). Abnormal ECGs are a feature of ischaemic heart disease and when the patient presents with a possible acute myocardial infarction, decisions about admission and treatment are based on ECG abnormalities. ${ }^{1} \mathrm{~A}$ recent study ${ }^{2}$ also showed that abnormal electrocardiographs are a common feature in patients with heart failure.

The ability of A\&E doctors to recognise ECG abnormalities has been tested in several studies. $^{3-8}$ In our own centre we showed that $>50 \%$ of ECGs are technically misinterpreted by doctors in $A \& E$ when compared to a cardiologist's report. However, serious errors which may affect medical management are much rarer (3-4\%). ${ }^{8}$ Improving the ECG reporting skills of $A \& E$ senior house officers has been shown to reduce serious errors. ${ }^{8}$ ECGs are performed by trained cardiographers and technicians, and the reporting skills of these paramedical workers have been shown to be superior to those of the senior house officers requesting the examination. ${ }^{9}$ In this present study we evaluated the effect of a technician report written at the time of the investigation on the electrocardiograph reporting ability of $A \& E$ and medical senior house officers.

\section{Methods}

ELECTROCARDIOGRAPH TRAINING

The A\&E doctors receive a tutorial on the interpretation of ECGs by one of the consultant cardiologists near the beginning of their six month post, and guidance notes on this topic are included in an A\&E handbook which is given to each of them. Senior house officers working within the Directorate of Medicine and responsible for medical admissions receive teaching on an informal basis and in a less structured way than senior house officers in the A\&E department.

At the beginning of the study the senior house officers in A\&E and medicine were advised that the cardiac technicians would be making an unofficial report on the ECGs performed on patients presenting to the $A \& E$ department by means of a sticker attached to the back of the recording (fig 1). It was emphasised that this was to be used as a guide only, and that the accuracy of this report should not necessarily be relied upon. Thus the final responsibility for interpretation remained with the examining doctor.

The cardiac technicians work five days a week from 0900 to 1700 hours. ECGs recorded by technicians on Monday, Wednesday, and Friday were interpreted by the technicians for one half of the study period and those recorded on Tuesday and Thursday for the other half. At all other times, and occasionally during the working week at times of exceptional workload, the nursing staff in the $A \& E$ 


\begin{tabular}{l|l|l|l}
\multicolumn{3}{|c}{$\begin{array}{r}\text { Cardiology Department } \\
\text { Technical Staff Report } \\
\text { No Significant Abnormalities }\end{array}$} \\
\hline Rhythm & Main Abnormalities noted & \\
\hline SR & & \multicolumn{1}{|c}{ Acute / Old } & \\
\hline S Tachy & ST segment changes & \\
\hline S Brady & T wave changes & \\
\hline SVT & RBBB & \\
\hline VT & LBBB & \\
\hline A Fib & Partial RBBB & \\
\hline Other & Partial LBBB & \\
\hline & $1^{\circ}$ Block & \\
\hline & 2 Block & \\
\hline & $3^{\circ}$ Block & \\
\hline & LVH & \\
\hline
\end{tabular}

Figure 1 Self adhesive technical staff report sticker used for reporting electrocardiographs in an accident and emergency department.

department record ECGs. They were not asked to report on them. Thus only ECGs recorded by technicians during 0900-1700 hours were included in this study. It was therefore possible to carry out parallel studies of ECG interpretation by $A \& E$ and medical senior house officers, comparing interpretation when the ECG carried a technician's report and when it did not.

Patients for whom ECGs were recorded were identified over a two month period from the A\&E coding system on the departmental computer. The A\&E records, the ECG, and any inpatient notes (where applicable) of these patients were reviewed.

A consultant cardiologist (KSC) reported on the ECGs in isolation, without clinical information and without knowledge of the technician's or senior house officer's report; this was used as the standard. His interpretation was then compared to the report provided by the cardiac technicians, A\&E senior house officers, and medical senior house officers. The accuracy of their interpretation was scored on a

Table 1 Classification of grades of agreement

\begin{tabular}{lll}
\hline Grade & Definition & Criteria \\
\hline 1 & $\begin{array}{l}\text { Complete concordance } \\
\text { Minor disagreement }\end{array}$ & $\begin{array}{l}\text { Accurate interpretation of the electrocardiograph. } \\
\text { First degree heart block, ventricular ectopic beats, sinus tachycardia, sinus } \\
\text { bradycardia, minor non-specific T wave changes. } \\
\text { Left ventricular hypertrophy, right or left axis deviation, bundle branch block, } \\
\text { slow atrial fibrillation, isolated T wave inversion or non-specific ST segment } \\
\text { depression, identification of Q wave in a lead in which it is not significant, } \\
\text { Wolff-Parkinson-White syndrome. } \\
\text { ST segment depression or elevation, widespread T wave inversion or presence } \\
\text { of pathological Q waves, fast atrial fibrillation or other dysrhythmia. }\end{array}$ \\
\hline & $\begin{array}{l}\text { Disagreement } \\
\text { Significant disagreement, } \\
\text { immediate management }\end{array}$ & \\
\hline
\end{tabular}

Table 2 Grades of agreement of senior house officers' electrocardiograph report with and without a technician's prior report

\begin{tabular}{llllll}
\hline Error grade & AEE SHO (\%) & $\begin{array}{l}\text { AEE SHO } \\
\text { (\%) after } \\
\text { technicians report }\end{array}$ & $\begin{array}{l}\text { Medical } \\
\text { SHO (\%) }\end{array}$ & $\begin{array}{l}\text { Medical SHO } \\
\text { (\%) after } \\
\text { technicians report }\end{array}$ & $\begin{array}{l}\text { Technician } \\
\text { only }\end{array}$ \\
\hline 1 & $47(43)$ & $48(59)$ & $33(57)$ & $23(56)$ & $78(61)$ \\
2 & $17(16)$ & $14(17)$ & $4(7)$ & $7(17)$ & $15(12)$ \\
3 & $27(25)$ & $14(17)$ & $10(17)$ & $7(17)$ & $24(19)$ \\
4 & $18(17)$ & $6(7) \star$ & $11(19)$ & $4(10) \dagger$ & $12(9)$ \\
\hline
\end{tabular}

SHO, senior house officer; $A \& E$, accident and emergency

$\star P<0.05$, grade $4 v$ combined grades 1,2 , and 3 (Fisher's exact test), A\&E senior house officer. †NS, grade $4 v$ combined grades 1,2 , and 3 , medical senior house officer. scale from 1 to 4 using the grading system shown in table $1 .^{8}$ Misinterpretations included the failure to detect an abnormality (false negative) and the reporting of an abnormality when none existed (false positive). The assessor was blinded to the identity of the author of the electrocardiograph report, whether it was technician or senior house officer.

\section{STATISTICAL ANALYSIS}

Values are given as mean (SD). The distribution of error gradings was compared by Fisher's exact test. The levels of agreement between technicians and doctors was tested using the $\kappa$ statistic. This latter test shows the level of agreement between observers which is better than chance alone. Thus, perfect agreement is 1.0 and agreement by chance alone is 0 . A $\kappa$ statistic of $0.61-0.8$ shows good agreement and $0.41-0.6$ shows moderate agreement.

\section{Results}

Three hundred and sixty five cases were identified. In 25 cases the ECGs were missing, and $95 \mathrm{~A} \& \mathrm{E}$ or hospital notes were unavailable during the audit period; thus 245 ECGs and case records were used in the analysis. In seven cases, although an electrocardiograph was present, no report was provided. Of the remainder, 129 were reported on by a cardiac technician before the senior house officer's report and 109 were reported by senior house officers only without a prior technician's report. The cardiologist reported 68/238 The error gradings for the technicians, $A \& E$ senior house officers, and medical senior house officers, when compared to the cardiologist's report, are shown in table 2. Overall, 121 patients were admitted.

Table 2 shows that the number of serious errors of interpretation (grade 4) was reduced from $18(17) \%$ to $6(7) \%(P<0.05$, Fisher's exact) when the technician provided a report for the A\&E senior house officers. Similarly, $(29 \%)$ of the ECGs to be completely normal. 
Table 3 Grades of agreement between technicians and senior house officers (SHOs) in accident and emergency (AE्EE)

\begin{tabular}{llrlll}
\hline & & \multicolumn{3}{c}{ Technician } \\
\cline { 3 - 6 } & $\begin{array}{l}\text { Error } \\
\text { grade }\end{array}$ & 1 & 2 & 3 & 4 \\
\hline A\&E SHO & 1 & 39 & 2 & 5 & 1 \\
& 2 & 5 & 6 & 1 & 2 \\
& 3 & 4 & 2 & 7 & 1 \\
& 4 & 3 & 0 & 0 & 3 \\
\hline
\end{tabular}

Table 4 Grades of agreement between senior house officers (SHOs) in medicine and accident and emergency ( $A \mathcal{E} E$ )

\begin{tabular}{llrlrl}
\hline & & \multicolumn{4}{c}{ Medical SHO } \\
\cline { 3 - 6 } & $\begin{array}{l}\text { Error } \\
\text { grade }\end{array}$ & 1 & 2 & 3 & 4 \\
\hline A\&E SHO & 1 & 26 & 4 & 2 & 1 \\
& 2 & 6 & 5 & 2 & 2 \\
& 3 & 5 & 1 & 10 & 3 \\
& 4 & 6 & 0 & 2 & 7 \\
\hline
\end{tabular}

the number of grade 4 errors made by medical senior house officers was reduced from $11(19) \%$ to $4(10) \%$ (NS) after a prior technicians report.

Table 3 shows the agreement between technicians and $A \& E$ senior house officers when compared to the consultant's report. The $\kappa$ statistic $(0.45)$ showed moderately good agreement between the interpretation grades of $A \& E$ senior house officers and technicians. Table 4 shows the agreement between the $A \& E$ and medical senior house officers. The $\kappa$ statistic (0.42) again showed moderately good agreement between senior house officers in the two departments for all grades of interpretation.

The outcome of nine patients who were discharged home with a grade 4 error of ECG interpretation is shown in table 5 . In four cases the misinterpretation was by the technician, in

Table 5 Number of grade 4 errors made by cardiographers (ECG Tech), senior house officers in accident and emergency ( $A \mathcal{E} E S H O$ ) and medicine (Med SHO), and outcome of patients who were discharged or died

\begin{tabular}{|c|c|c|c|c|}
\hline $\begin{array}{l}\text { ECG } \\
\text { Tech }\end{array}$ & $\begin{array}{l}A \mathscr{E} E \\
S H O\end{array}$ & $\begin{array}{l}\text { Med } \\
\text { SHO }\end{array}$ & ECG error & Outcome \\
\hline \multirow[t]{3}{*}{1} & & & Old inferior infarct & ?Urinary infection \\
\hline & 1 & 1 & ST segment depression & Collapse \\
\hline & 1 & & Old inferior infarct & Angina \\
\hline 1 & 1 & & Old inferior infarct & Fall \\
\hline 1 & & & Wrongly diagnosed as old infarct & Faint \\
\hline \multirow[t]{6}{*}{1} & & & Old inferior infarct & Breathlessness \\
\hline & 1 & & Old inferior infarct & Angina \\
\hline & 1 & & ST segment depression & Breathlessness and angina \\
\hline & 1 & & Old inferior infarct & Breathlessness \\
\hline & 1 & & Old inferior infarct & Ventricular fibrillation-DIED \\
\hline & 1 & 1 & Acute anterolateral infarct & DIED \\
\hline 4 & 8 & 2 & TOTAL & \\
\hline
\end{tabular}

Table 6 Numbers of grade 4 errors by cardiographers (ECG Tech), senior house officers in accident and emergency ( $A \mathcal{E} E S H O$ ) and medicine (Med SHO) in admitted patients

\begin{tabular}{llll}
\hline ECG Tech & AEE SHO & Med SHO & ECG error \\
\hline 3 & 1 & 1 & Overdiagnosis of infarction \\
1 & 2 & 4 & Missed old infarction \\
1 & 2 & 2 & Missed acute infarction \\
2 & 2 & 2 & Missed fast atrial fibrillation \\
1 & 2 & 1 & Overdiagnosis of fast atrial fibrillation \\
& & 1 & Overdiagnosis of heart block \\
& 1 & 1 & Missed atrial flutter \\
8 & 5 & 1 & Missed ST elevation/depression \\
& 1 & 13 & Missed right ventricular hypertrophy \\
\hline
\end{tabular}

six cases by the A\&E senior house officer, and in one case by the medical senior house officer. In six cases the misinterpretation was a failure to record or recognise an old myocardial infarction. In two cases significant ST segment change was not recognised and in one case the ECG was reported to show an old myocardial infarction when it was not present. Two patients died in the $\mathrm{A} \& \mathrm{E}$ department and in both cases grade 4 errors of interpretation were made by senior house officers. Table 6 shows the serious errors of interpretation made in patients who were admitted to hospital, which by definition could have resulted in inadequate immediate management. From among the 117 patients discharged, 18 ECGs (15\%) had no $A \& E$ doctors' interpretation recorded in the notes, yet on 17 of these a cardiac technician's report was present. Therefore, in only one case was an ECG requested by an A\&E doctor and recorded, but no formal report was written. This suggests that the cardiac technician's report was used by the $A \& E$ senior house officers instead of their own report.

\section{Discussion}

Doctors may be unaware of the thorough training programme that the cardiac technicians undergo at the Royal Hallamshire Hospital. Their qualifications include an Ordinary National Certificate and a Higher National Certificate in medical physics and physiological measurement. They also hold the Associateship of the Society of Cardiology Technicians by means of an examination based entry. By the very nature of their job, they are continually exposed to a large number of ECGs, and thus quickly gain experience in recognising normality from abnormality. It seemed a missed opportunity not to make use of this experience, in much the same way as radiographers use abnormal pattern recognition (a "red dot system") to draw attention to $x$ ray abnormalities. ${ }^{10}$

We judged the ECG interpretation made by technicians and senior house officers against that of a gold standard-the consultant cardiologist. By using a single cardiologist's report, we recognise that we have no information on the inter- and intraobserver errors of this standard. Even consultant cardiologists disagree on ECG reports, but we do not believe that there would be disagreement about grade 4 errors, which are the important clinical ones on which we have based our assessment in this study. The error gradings of the reported ECGs were similar throughout the three groups and comparable to those found in other studies. ${ }^{468}$ When the error gradings of the technicians only are considered, the percentage grade 4 errors is similar to that found when the two medical staff groups reported on the same ECGs with the benefit of the prior technician's report. However, when the doctors reported ECGs without a prior technical report there was a doubling of the serious error rate $(17 \% v$ $7 \%$ and $19 \% \quad v 10 \%$, respectively). This suggests that the presence of a technician's 
report can have an important part to play in reducing these more serious misinterpretations.

It is of concern that, despite a teaching programme and the issuing of guidelines, the senior house officers in $\mathrm{A} \& \mathrm{E}$ were still making a significant percentage of grade 4 errors. Though only half the number of ECGs interpreted by medical senior house officers were analysed, they fared little better. Tables 5 and 6 , which describe the errors, illustrate their importance in clinical practice.

HOW CAN THESE ERRORS BE REDUCED?

Previous studies have investigated formal teaching of medical staff in ECG interpretation, one of which included eight hours of teaching over a 14 day period, ${ }^{7}$ after which no improvement in interpretation was found! However, if it is possible to train technicians, cardiographers, and nurses to interpret ECGs accurately, ${ }^{9}$ so it should be possible to train doctors. What is required is the same commitment from the trainers and the trainees to learn the skill. We think ECG interpretation should be included in the undergraduate curriculum, with refresher courses, feedback, and regular audit as part of postgraduate general medical training. Although using other trained personnel helps reduce errors, as we have shown, we should not accept the loss of this skill from doctors to paramedical staff. Modern ECG recorders offer computer based interpretation, but these have been shown to be inferior to that of a trained cardiologist. ${ }^{11}$ They frequently overinterpret abnormalities, which may lead to unnecessary admissions and treatment. We do not know whether the use of interpretative electrocardiographic recorders would confer the same benefit as the use of prior technical reporting, as demonstrated in this study.

\section{CONCLUSION}

We believe that ECG reports by technicians, despite the constraints of their working hours, can be a valuable supplement to ECG interpretation in an A\&E department. This makes use of the technicians' expertise and enhances their job satisfaction.

We thank Janet Smith and Paul Reynolds in the Central Sheffield University Hospital Audit office for data handling; Mrs Patricia Matthewman, senior chief cardiac technician, for all support and advice with the design of the sticker; Fion Coates, senior technician, for help in coordination of the study; and Annette Bowes-Dawson for typing the manuscript.

1 Verstraete M. Thrombolytic treatment. BMJ 1995; 311: 582-3.

2 Davie AP, Francis CM, Love MP, Caruana L, Starkey IR, Shaw TRD, et al. Values of the electrocardiograph in identifying heart failure due to left ventricular systolic dysfunction.BMJ 1996;312:222.

3 Emerson PA, Russell HJ, Wyatt J, Crichton N, Pantin CFA Morgan AD, et al. An audit of doctors management of patients with chest pain in the Accident \& Emergency department. Q J Med 1989;263:213-20.

4 McCallion WA, Templeton PA, McKinney LA, Higginson JDS. Missed myocardial ischaemia in the accident \& emergency department: ECG a need for audit. Arch Emerg Med 1991;8:102-7.

5 Morrison WG, Swann IJ. Electrocardiograph interpretation by junior doctors. Arch Emerg Med 1990;7:108-10.

6 Westdrop EJ, Gratton MC, Watson WA. Emergency department interpretation of electrocardiographs. Ann Emerg Med 1992;21:541-44.

7 Gjorup T, Kelbaek H, Nielson D, Kreiner S, Godfriedsen J Interpretation of the electrocardiograph in suspected myocardial infarction: a randomised controlled study of the effect of a training programme to reduce inter-observer variation. J Intern Med 1992;231:407-12.

8 White T, Woodmansey PA, Ferguson DG, Channer KS Improving the interpretation of electrocardiographs in an accident \& emergency department. Postgrad Med J accident \& em

9 Woodmansey PA, White T, Channer KS. Formal teaching can reduce serious errors in interpretation. BMJ 1995;310 468.

10 Berman L, DeLacey G, Twomey E, Twomey B, Welch T, Eban R. Reducing errors in the accident and emergency department: a simple method using radiographers. BMJ 1985;290:421-2.

11 Willems JL, Abreu-Lima C, Arnaud P, VanBemmel JH, Brohet C, Degani R, et al. The diagnostic performance of computer programs for the interpretation of electrocardiographs. N Engl J Med 1991;325:1767-73. 